\title{
Estimated Prevalence and Incidence of Amyotrophic Lateral Sclerosis and SOD1 and C9orf72 Genetic Variants
}

\author{
Carolyn A. Brown ${ }^{a, b}$ Cathy Lally ${ }^{a}$ Varant Kupelian ${ }^{c}$ W. Dana Flanders ${ }^{a, b}$ \\ ${ }^{a}$ Epidemiologic Research and Methods LLC, Atlanta, GA, USA; ${ }^{b}$ Department of Epidemiology, Rollins School of \\ Public Health, Atlanta, GA, USA; 'Biogen, Cambridge, MA, USA
}

\section{Keywords}

Epidemiology · Amyotrophic lateral sclerosis · Prevalence · Incidence $\cdot$ Genetics

\begin{abstract}
Introduction: Amyotrophic lateral sclerosis (ALS) is a rare neurological disorder characterized by progressive deterioration of motor neurons. Assessment of the size/geographic distribution of the ALS population, including ALS with genetic origin, is needed to understand the burden of the disease and the need for clinical intervention and therapy. $\mathbf{O b}$ jectives: The main objective of this study was to estimate the number of prevalent and incident ALS cases overall and superoxide dismutase 1 (SOD1) and chromosome 9 open reading frame 72 (C9orf72) ALS in 22 countries across Europe (Belgium, France, Germany, Ireland, Italy, Netherlands, Norway, Russia, Spain, Sweden, and UK), North America (USA and Canada), Latin America (Argentina, Brazil, Colombia, Mexico, and Uruguay), and Asia (China, Japan, South Korea, and Taiwan). Methods: A comprehensive literature search was conducted to identify population-based studies reporting ALS prevalence and/or incidence rates. Pooled prevalence and incidence rates were obtained using a meta-anal-
\end{abstract}

karger@karger.com

(c) 2021 S. Karger AG, Basel

www.karger.com/ned

Karger" ysis approach at the country and regional geographic level. A country-level pooled estimate was used when $\geq 2$ studies were available per country and geographic regional pooled estimates were used otherwise. The proportion of cases with a SOD1 or C9orf72 mutation among sporadic (SALS) and familial (fALS) cases were obtained from a previous systematic review and meta-analysis. Results: Pooled prevalence rates (per 100,000 persons) and incidence rates (per 100,000 person-years) were 6.22 and 2.31 for Europe, 5.20 and 2.35 for North America, 3.41 and 1.25 for Latin America, 3.01 and 0.93 for Asian countries excluding Japan, and 7.96 and 1.76 for Japan, respectively. Significant heterogeneity in reported incidence and prevalence was observed within and between countries/geographic regions. The estimated number of 2020 ALS cases across the 22 countries is 121,028 prevalent and 41,128 incident cases. The total estimated number of prevalent SOD1 cases is 2,876 cases, of which, 1,342 (47\%) were fALS and 1,534 (53\%) were SALS, and the number of incident SOD1 cases is 946 (434 [46\%] fALS and 512 [54\%] sALS). The total estimated number of prevalent C9orf72 cases is 4,545 (1,198 [26\%] fALS, 3,347 [74\%] sALS), and the number of incident C9orf72 cases is 1,706 (450 [26\%] fALS and 1,256 [74\%] sALS). Discussion: The estimated number of patients with SOD1 and C9orf72 ALS suggests that although 
the proportions of SOD1 and C9orf72 are higher among those with $\mathrm{fALS}$, the majority of SOD 1 and C9orf72 ALS cases may be found among those with sALS (about 53 and 74\%, respectively). These results suggest that classification of fALS based on reported family history does not capture the full picture of ALS of genetic origin.

(c) 2021 S. Karger AG, Basel

\section{Introduction}

Amyotrophic lateral sclerosis (ALS) is a progressive, fatal, neurodegenerative disease involving both upper and lower motor neurons. Those affected experience progressive muscle weakness, which eventually includes difficulty swallowing and breathing. Typically, patients die of respiratory failure, with a median survival of 2-4 years after onset [1]. In approximately $90-95 \%$ of the cases, ALS is sporadic (sALS), but about $5-10 \%$ have a family history (familial ALS [fALS]) [2]. Epidemiologic investigations of ALS have been complicated by difficulties in determining the specific date of onset and the potentially long period of time between onset of pathological changes and clinical disease manifestation [3]. Most of the studies of ALS incidence and prevalence using population-based designs have been conducted in Europe, where the estimates are fairly uniform; the incidence and prevalence in many other regions of the world are not as well-characterized [3].

Assessment of the size and geographic distribution of the ALS population, including ALS due to genetic origin, is needed to understand the burden of disease, as well as the need for clinical intervention and therapy. Populationbased registries are essential in understanding the epidemiology and natural history of ALS and help improve clinical assessment of ALS [3, 4]. Furthermore, comparing trends in prevalence, diagnosis, and treatment from population registries across countries and regions can help identify potential differences in disease occurrence and outcomes [5].

Since 1993, genetic studies have identified over 20 genes that are involved in the pathogenesis of ALS [6], with the most common being the chromosome 9 open reading frame (C9orf72) repeat expansions and mutations in the superoxide dismutase (SOD1), TAR DNAbinding protein (TARDBP), and fused in sarcoma genes [2]. Even though specific genetic factors are now recognized as contributing to fALS, the etiology of sALS been less understood and is of growing interest [7]. A metaanalysis of 111 studies of ALS genetic mutations found significant differences in the frequencies of mutations in European versus Asian ALS cases; the most common mu- tation in European cases was C9orf72, whereas the most common mutation in Asian cases was SOD1 [2]. Additionally, some evidence suggests there is lower incidence of ALS in individuals with mixed ancestral origin other than Spanish [3, 8-10]. These results highlight a need for genetic testing of patients with ALS, tailored to geographic location and ethnic background.

The objective of this comprehensive literature review and meta-analysis was to estimate the number of prevalent and incident cases of ALS overall and of SOD1 and C9orf72 ALS in 22 countries across geographic regions in Europe (Belgium, France, Germany, Ireland, Italy, Netherlands, Norway, Russia, Spain, Sweden, and UK), North America (USA and Canada), Latin America (Argentina, Brazil, Colombia, Mexico, and Uruguay), and Asia (China, Japan, South Korea, and Taiwan).

\section{Methods}

\section{Literature Review}

All the searches for ALS incidence and prevalence were conducted in December 2018 and updated on August 6, 2020. PubMed and Embase (Embase.com) were searched for the years 2000-2020 using a combination of the relevant subject headings and text words to represent ALS, incidence and prevalence, and the countries of interest. Records were limited to English language, human, and publication dates from 2000 to date. The records were downloaded to EndNote and de-duplicated. The search strategy included the following terms: "Amyotrophic Lateral Sclerosis"[Mesh]; Amyotrophic Lateral Sclerosis[Title/Abstract]; ALS[Title/Abstract]; ((Lou-Gehrig*[Title/Abstract]) OR Gehrig*[Title/Abstract]; "Prevalence"[Mesh]; "incidence" [Mesh]; prevalen*[Title/ Abstract] OR inciden*[Title/Abstract]; occurr*[Title/Abstract] OR frequen*[Title/Abstract] OR "first ever"[Title/Abstract]; "Cohort Studies" [MeSH Terms]; epidemiology[Subheading]).

Additional sources within the same scope were identified from the references reviewed. The additional sources were not restricted to the years 2000-2020 and could potentially include previous years for relevant literature.

Articles queried were compiled and screened based on relevance. A total of 3,116 articles were initially identified from the literature search. Articles deemed not relevant based on a review of titles and abstracts were excluded $(n=2,845)$. Titles deemed not relevant were case studies, studies of treatment and treatment outcomes, studies whose population was limited to fALS or sALS cases from specific pedigrees/families, studies whose population was likely not representative of the country's population, studies not from a country of interest, or whose data were gathered entirely before 1995. The remaining 271 articles underwent an in-depth full-text review. After this review, 195 studies were excluded, leaving 76 that provided information on ALS incidence, prevalence or mutation prevalence, or background information. Two additional studies within the same scope were identified from the references identified after review of the 76 relevant articles, for a total of 78 publications cited in the report. 


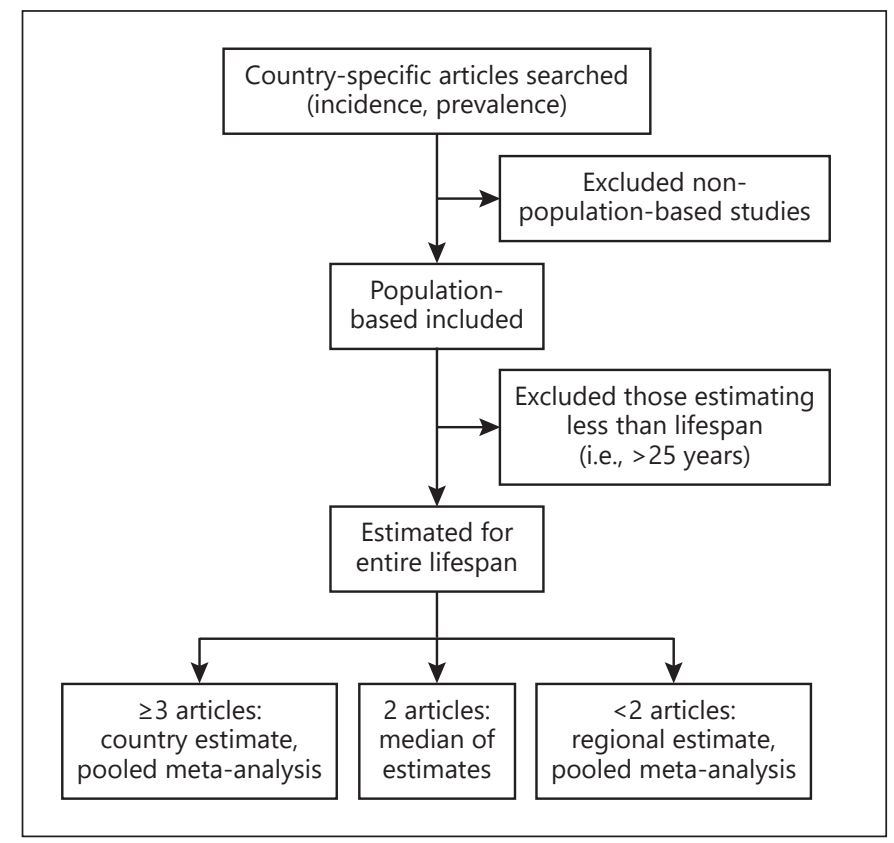

Fig. 1. Inclusion and estimation method.

\section{Analytic Approach}

Incidence and prevalence are reported per 100,000 person-years and population, respectively. Pooled prevalence and incidence rates were estimated at both the country and regional geographic level, with the same methods applied for both prevalence and incidence estimates (Fig. 1). In part because of substantial study-tostudy heterogeneity within each country, we include simple descriptive statistics for each country, including the number of studies and, when applicable, the median and range of the prevalence (or incidence rate) estimates based on the included studies. When we identified 3 or more population-based studies reporting prevalence/incidence for a given country, estimates were also calculated for that country using meta-analysis (random-effects models fitted using R package "metafor" with restricted maximum-likelihood estimators) for completeness. If we found only 2 eligible studies for a given country, we only included the descriptive results noted above. Finally, if we found either a single population-based study or no studies reporting prevalence/incidence of ALS for a given country, the regional estimate was used for that country with the exception of the USA and Japan, where a single study providing nationwide estimates was available (the National ALS Registry in the USA [11] and a nationwide survey of ALS in Japan [12]); regional estimates were calculated using a meta-analysis in $\mathrm{R}$, where random-effects models were fitted using restricted maximum-likelihood estimators. Regions were defined by the continent: Asian regional (includes China, South Korea, and Taiwan), European regional (includes Belgium, France, Germany, Ireland, Italy, Netherlands, Norway, Russia, Spain, Sweden, and UK), North American regional (includes Canada and the USA), and Latin American regional (includes Argentina, Brazil, Colombia, Mexico, and Uruguay).

The proportion of SOD1 and C9orf72 mutations among sALS and fALS cases was obtained from a previous systematic review and meta-analysis study by Zou et al. [2]. Asian estimates were used for
Table 1. Descriptive summary of included incidence studies

\begin{tabular}{lcll}
\hline Country & $\begin{array}{l}\text { Studies, } \\
n\end{array}$ & Median & $\begin{array}{l}\text { Range of incidence } \\
\text { estimates per 100,000 }\end{array}$ \\
\hline Argentina & 1 & 3.17 & NA \\
Belgium & 0 & - & - \\
Brazil & 1 & 0.40 & NA \\
Canada & 3 & 3.01 & $2.24-3.29$ \\
China & 3 & 0.77 & $0.60-1.65$ \\
Colombia & 1 & 1.40 & NA \\
France & 4 & 3.17 & $2.53-4.90$ \\
Germany & 3 & 2.40 & $1.80-2.60$ \\
Ireland & 3 & 1.97 & $1.90-2.10$ \\
Italy & 18 & 2.59 & $1.45-4.17$ \\
Japan & 1 & 1.76 & NA \\
Mexico & 0 & - & - \\
Netherlands & 1 & 2.27 & NA \\
Norway & 2 & 2.06 & $2.00-2.13$ \\
Russia & 1 & 1.25 & NA \\
South Korea & 1 & 1.68 & NA \\
Spain & 2 & 2.07 & $1.40-2.74$ \\
Sweden & 1 & 3.73 & NA \\
Taiwan & 1 & 0.54 & NA \\
UK & 4 & 1.67 & $1.06-2.44$ \\
Uruguay & 1 & 1.42 & NA \\
USA & 2 & 1.86 & $1.52-2.20$ \\
\hline
\end{tabular}

NA, not applicable.

China and Japan, and European estimates were used for all other countries. To calculate the proportion of people in each country with ALS and a SOD1 mutation, these estimates were applied to each country using Equation (1):

$$
P_{S O D 1, c}=p_{A L S, c} \times\left[\left(p_{F A L S} \times P(S O D 1 \mid F A L S)+\left(1-p_{F A L S}\right) \times P(S O D 1 \mid S A L S)\right)\right]
$$

where $P_{\mathrm{SOD} 1, c}$ is the proportion of people with ALS and a SOD1 mutation in the country; $p_{\mathrm{ALS}, c}$ is the prevalence of ALS in country; $p_{\text {FALS }}$ is the proportion of fALS cases among those with ALS; is the proportion of SOD1 among fALS cases; and is the proportion of SOD1 among sALS cases. The same method was applied to estimate cases of C9orf72 by country.

\section{Results}

\section{Incidence}

Country-specific medians and meta-analysis estimates were calculated for 11 countries (Canada, China, France, Germany, Ireland, Italy, Japan, Norway, Spain, USA, and $\mathrm{UK})$, and regional meta-analysis estimates were used for the remaining 11 countries including Latin American countries (Argentina, Brazil, Colombia, Mexico, and Uruguay), European countries (Belgium, Netherlands, Russia, and Sweden), and Asian countries (Taiwan and 
Table 2. Incidence estimates by country

\begin{tabular}{llllll}
\hline Country & Incidence & $95 \%$ CI/range* & Regional/Country & Region & Method used \\
\hline Argentina & 1.25 & $0.54-2.89$ & Regional & Latin America & Meta-analysis \\
Belgium & 2.31 & $2.08-2.55$ & Regional & Europe & Meta-analysis \\
Brazil & 1.25 & $0.54-2.89$ & Regional & Latin America & Meta-analysis \\
Canada & 3.08 & $2.61-3.63$ & Country & & Meta-analysis \\
China & 0.92 & $0.50-1.67$ & Country & & Meta-analysis \\
Colombia & 1.25 & $0.54-2.89$ & Regional & Latin America & Meta-analysis \\
France & 3.32 & $2.50-4.41$ & Country & & Meta-analysis \\
Germany & 2.26 & $1.84-2.79$ & Country & & Meta-analysis \\
Ireland & 1.99 & $1.84-2.15$ & Country & & Meta-analysis \\
Italy & 2.45 & $2.17-2.76$ & Country & & Meta-analysis \\
Japan & 1.76 & $1.76-1.76$ & Country & & Single study \\
Mexico & 1.25 & $0.54-2.89$ & Regional & Latin America & Meta-analysis \\
Netherlands & 2.31 & $2.08-2.55$ & Regional & Europe & Meta-analysis \\
Norway & 2.06 & $2.00-2.13$ & Country & & Median \\
Russia & 2.31 & $2.08-2.55$ & Regional & Europe & Meta-analysis \\
South Korea & 0.93 & $0.57-1.51$ & Regional & East Asia & Meta-analysis \\
Spain & 2.07 & $1.40-2.74$ & Country & & Median \\
Sweden & 2.31 & $2.08-2.55$ & Regional & Europe & Meta-analysis \\
Taiwan & 0.93 & $0.57-1.51$ & Regional & East Asia & Meta-analysis \\
UK & 1.62 & $1.08-2.43$ & Country & & Meta-analysis \\
Uruguay & 1.25 & $0.54-2.89$ & Regional & Latin America & Meta-analysis \\
USA & 1.86 & $1.52-2.20$ & Country & & Median \\
\hline
\end{tabular}

CI, confidence interval. *For meta-analysis estimates, the data given are the $95 \%$ CIs; for median estimates, the data given are the ranges in study estimates.

South Korea) [12-63]. Motor neuron disease and related disorders were included in the estimate by Fong et al. [16] from Hong Kong. Although the estimate is not specific to ALS only, it was included in the China estimate. Additionally, Japan was not included in the Asian regional estimate due to evidence of higher incidence of ALS among Japanese populations [64].

A descriptive summary by country is shown in Table 1. The pooled or median estimates of incidence, including details by country, are shown in Table 2. For most of the countries for which we calculated a country-specific estimate, the median of the reported result and the metaanalysis result were similar.

The regional incidence rates for Europe $(2.31,95 \%$ confidence interval [CI] 2.08-2.55) and North America $(2.35,95 \%$ CI 1.76-3.15) were higher than those for Asia $(0.93,95 \%$ CI $0.57-1.51)$ and Latin America (1.25, 95\% CI $0.54-2.89)$. Results of the meta-analysis by country and region are shown in Figures 2 and 3.

\section{Prevalence}

The same methods of estimation were used for prevalence as those used for incidence. Italy, Ireland, and Nor- way were the only countries for which 3 or more countryspecific studies were performed and therefore the only countries with country-specific meta-analysis prevalence estimates $[16,17,26,27,31,33,38,42,44,46-49,52,54-$ $58,60,61,63,65-70]$. For the USA, prevalence estimates for ALS were obtained from the National ALS Registry, which constitutes the most comprehensive assessment of ALS through large national databases (Medicare, Medicaid, and Veteran's Administration) and self-enrollment via a web portal with validation by a screening questionnaire [71]. The US prevalence rate was used for Canada as there were no prevalence studies from Canada. A descriptive summary by country is shown in Table 3. Prevalence estimates are shown in Table 4, with details about which type of estimate was used (country- or region-specific and meta-analysis or median value). Much as for incidence, the prevalence in Europe (6.22, 95\% CI 5.247.40) and North America (5.20, single study) was higher than those in Asia (3.01, 95\% CI 1.99-4.56) and Latin America (3.41, 95\% CI 1.71-6.82), again, with the exception of Japan (7.96, single study). All studies included for the prevalence estimates, by country and region, respectively, are shown in Figures 4 and 5. 


\section{Canada}

Lareau-Trudel 2013

Golby 2016

Bonaparte 2007

RE model for subgroup ( $p=0.20 ; R^{2}=35.3 \%$ )

Zhou Qian 2018

Xu 2020

Fong 2005

RE Model for Subgroup ( $p=0.00 ; R=99.6 \%$ )

\section{France}

Preux 2000

Masseret 2013

Marin 2014

Marin 2009

RE model for subgroup ( $p=0.00 ; l^{2}=91.8 \%$ )

\section{Germany}

Uenal 2014

Rosenbohm 2017

RE model for subgroup ( $p=0.00 ; R^{2}=91.4 \%$ )

Ireland

Traynor 1999

Otoole 2008

Logroscino 2010.1

RE model for subgroup ( $p=0.55 ; R^{2}=0.0 \%$ )

\section{Italy}

Tesauro 2017

Scialo 2016

Ragonese 2012

Pugliatti 2013

Piemonte 2001

Palese 2019

Nicoletti 2016

Mandrioli 2014

Mandrioli 2003

Logroscino 2005

Giagheddu 2013

Georgoulopoulou 2011

Drigo 2013

Cima 2009

Chio 2017

Chio 2008

Beghi 2007

Bandettini di Poggio 2013

RE model for subgroup $\left(p=0.00 ; l^{2}=91.5 \%\right)$

UK

Logroscino 2010.2

Jonnston 2006

Forbes 2007

Abhinav 2007

RE model for subgroup $\left(p=0.00 ; 1^{2}=97.7 \%\right)$

RE model for all studies $\left(p=0.00 ; l^{2}=98.4 \%\right)$

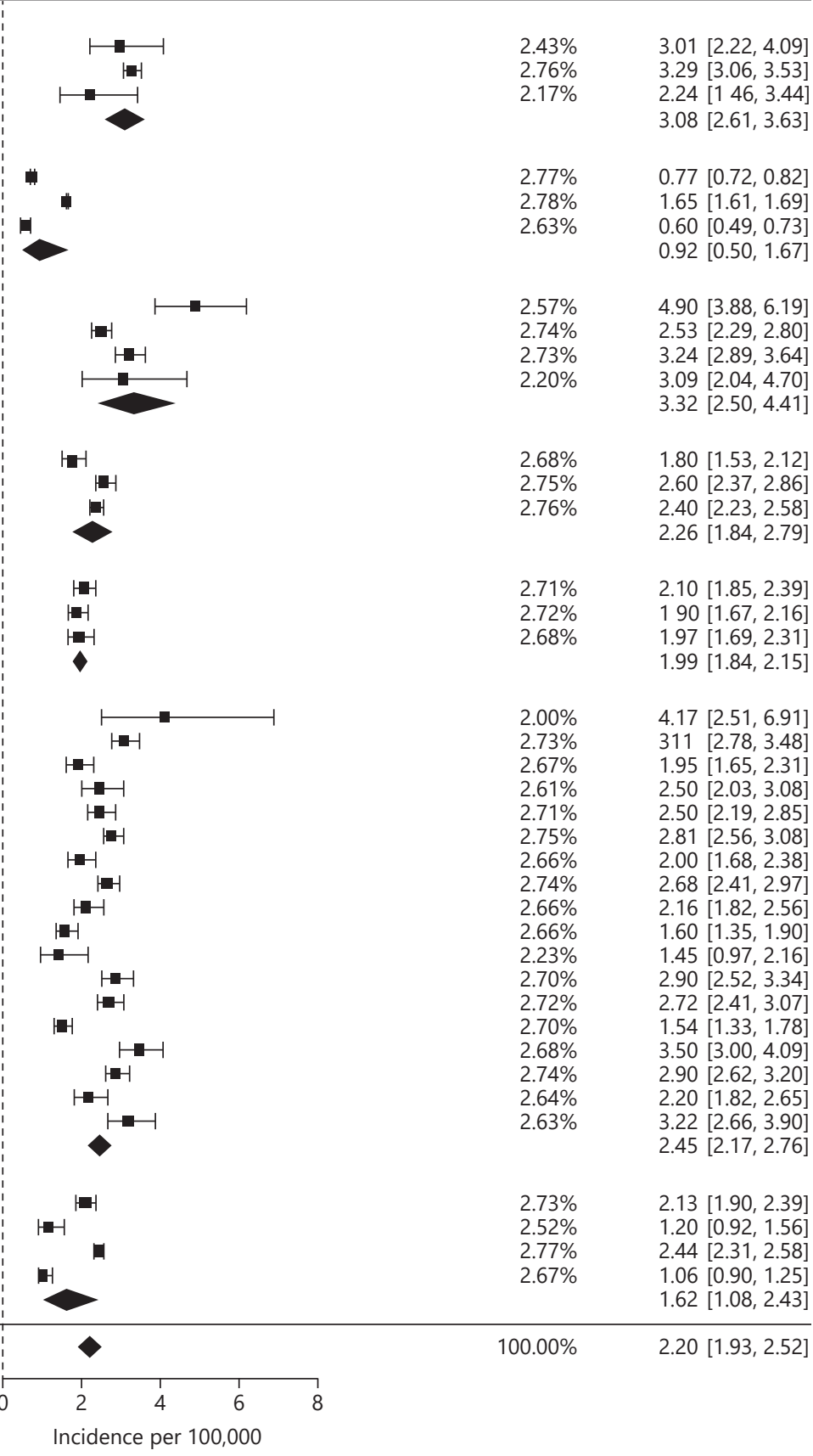

Fig. 2. Country-specific incidence forest plot (meta-analysis in R). CI, confidence interval; RE, random effects. 


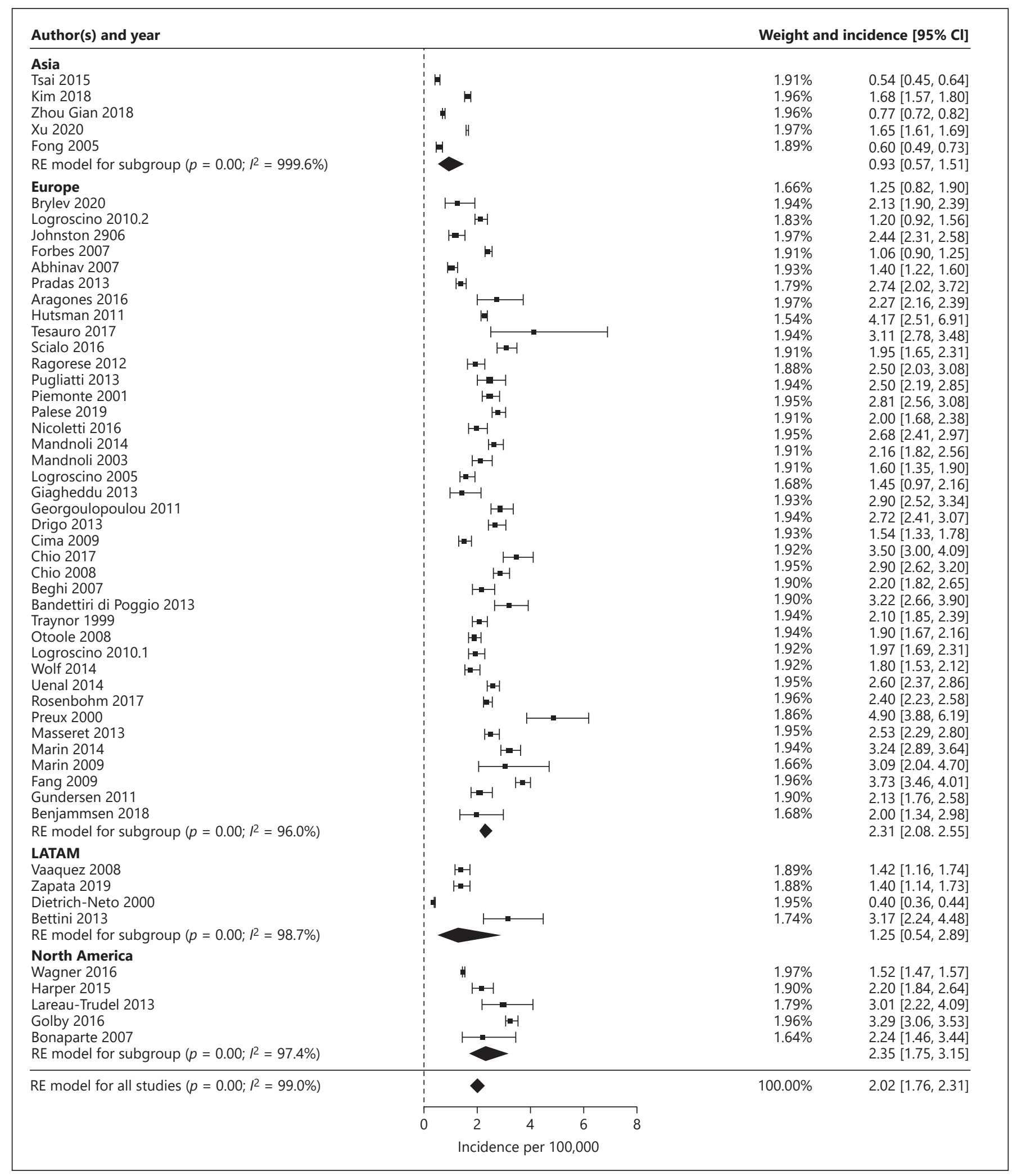

Fig. 3. Region-specific incidence forest plot (meta-analysis in R). CI, confidence interval; RE, random effects.

Prevalence and Incidence of Amyotrophic Lateral Sclerosis
Neuroepidemiology 2021;55:342-353 DOI: $10.1159 / 000516752$ 
Table 3. Descriptive summary of included prevalence studies

\begin{tabular}{llll}
\hline Country & $\begin{array}{l}\text { Studies, } \\
n\end{array}$ & Median & $\begin{array}{l}\text { Range of prevalence } \\
\text { estimates per 100,000 }\end{array}$ \\
\hline Argentina & 1 & 8.86 & NA \\
Belgium & 1 & 3.20 & NA \\
Brazil & 2 & 3.10 & $1.20-5.00$ \\
Canada & 0 & - & - \\
China & 2 & 2.99 & $2.91-3.07$ \\
Colombia & 1 & 4.90 & NA \\
France & 0 & - & - \\
Germany & 0 & - & - \\
Ireland & 3 & 6.40 & $4.70-7.20$ \\
Italy & 7 & 7.89 & $4.63-12.26$ \\
Japan & 1 & 7.96 & NA \\
Mexico & 0 & - & - \\
Netherlands & 1 & 8.51 & NA \\
Norway & 3 & 4.05 & $3.69-7.63$ \\
Russia & 0 & - & - \\
South Korea & 1 & 6.49 & NA \\
Spain & 2 & 6.89 & $5.40-8.38$ \\
Sweden & 0 & - & - \\
Taiwan & 2 & 2.06 & $2.04-2.09$ \\
UK & 2 & 4.03 & $3.99-4.06$ \\
Uruguay & 1 & 2.01 & NA \\
USA & 1 & 5.20 & NA \\
\hline
\end{tabular}

NA, not applicable.

\section{Estimated Case Number by Country}

The estimated number of cases for each included country, from 2019 to 2024, was calculated using country-specific population estimates. The 4 main data sources used for population estimates are the Eurostat database, the Centers for Disease Control and Prevention US Census Data population projections accessed and downloaded through CDC WONDER Statistics, Canada, and the World Population Prospects from the Population Division of the United Nations [72-75]. The prevalence estimates shown in Table 3 were applied directly to the population estimates for each country to estimate the total number of cases of ALS within each country (see online suppl. Table 2; see www. karger.com/doi/10.1159/000516752 for all online suppl. material).

\section{Prevalence of $f A L S$ and sALS}

The proportion of all fALS cases found by Byrne et al. [76] was 5.1\%. Online suppl. Table 3 shows the estimated number of fALS and sALS cases by country from 2019 to 2024. We assumed that $5.1 \%$ of all cases were familial in all countries.

\section{Prevalence of SOD1 and C9orf72 Mutations}

Percentage of fALS and sALS cases with SOD1 and C9orf72 mutations were taken from the meta-analysis conducted by Zou et al. [2]. Asian estimates were used for China and Japan, and European estimates were used for all other countries (Table 5). Online suppl. Table 3 shows the estimated ALS cases due to SOD1, ALS cases due to C9orf72, the number of persons living with SOD1 from fALS, the number of persons living with C9orf72 from fALS, the number of persons living with SOD1 from sALS, and the number of persons living with C9orf72 from sALS.

Pooled prevalence (per 100,000 persons) and incidence rates (per 100,000 person-years) were 6.22 and 2.31 for Europe, 5.20 and 2.35 for North America, 3.41 and 1.25 for Latin America, 3.01 and 0.93 for Asian countries excluding Japan, and 7.96 and 1.76 for Japan, respectively. Significant heterogeneity in reported incidence and prevalence was observed both within and between countries and geographic regions.

The estimated number of all ALS cases in 2020 across the 22 countries is 121,028 prevalent and 41,128 incident cases. The total estimated number of prevalent SOD1 cases is 2,876 cases, of which $1,342(47 \%)$ were fALS and $1,534(53 \%)$ were sALS, and the number of incident SOD 1 cases is 946 (434 [46\%] fALS and 512 [54\%] sALS). The total estimated number of prevalent $\mathrm{C} 9$ orf72 cases is 4,545 (1,198 [26\%] fALS and 3,347 [74\%] sALS), and the number of incident C9orf72 cases is 1,706 (450 [26\%] fALS and 1,256 [74\%] sALS).

\section{Discussion}

This comprehensive literature review and metaanalysis were used to estimate the incidence of ALS, the prevalence of ALS, and the prevalent and incident cases of both fALS and sALS due to SOD1 and C9orf72 mutations in 22 countries. These results provide support for regional differences in ALS $[1,77]$, with generally higher prevalence and incidence rates in Europe and North America than in Asia and Latin America. Similarly, the Global Burden of Disease Study 2016 reports the highest estimated prevalence for motor neuron disease overall in North America and Western Europe [78]. However, substantial heterogeneity was found both within regions and within countries, which may be partially explained by differences in the study design and inconsistency in ALS case definitions between studies $[1,77]$. 
Table 4. Prevalence estimates by country

\begin{tabular}{llllll}
\hline Country & Prevalence & $95 \%$ CI/range* & Regional/Country & Region & Method \\
\hline Argentina & 3.41 & $1.71-6.82$ & Regional & Latin America & Meta-analysis \\
Belgium & 6.23 & $5.24-7.40$ & Regional & Europe & Meta-analysis \\
Brazil & 3.10 & $1.20-5.00$ & Country & & Median \\
Canada & 5.20 & $5.20-5.20$ & Country & & Single country (USA) \\
China & 2.99 & $2.91-3.07$ & Country & & Median \\
Colombia & 3.41 & $1.71-6.82$ & Regional & Latin America & Meta-analysis \\
France & 6.23 & $5.24-7.40$ & Regional & Europe & Meta-analysis \\
Germany & 6.23 & $5.24-7.40$ & Regional & Europe & Meta-analysis \\
Ireland & 6.03 & $4.70-7.73$ & Country & & Meta-analysis \\
Italy & 7.85 & $6.12-10.07$ & Country & & Meta-analysis \\
Japan & 7.96 & $7.96-7.96$ & Country & & Single study \\
Mexico & 3.41 & $1.71-6.82$ & Regional & Latin America & Meta-analysis \\
Netherlands & 6.23 & $5.24-7.40$ & Regional & Europe & Meta-analysis \\
Norway & 5.29 & $3.19-8.79$ & Country & & Meta-analysis \\
Russia & 6.23 & $5.24-7.40$ & Regional & Europe & Meta-analysis \\
South Korea & 3.01 & $1.99-4.56$ & Regional & East Asia & Meta-analysis \\
Spain & 6.89 & $5.40-8.38$ & Country & & Median \\
Sweden & 6.23 & $5.24-7.40$ & Regional & Europe & Meta-analysis \\
Taiwan & 2.06 & $2.04-2.09$ & Country & & Median \\
UK & 4.03 & $3.99-4.06$ & Country & & Median \\
Uruguay & 3.41 & $1.71-6.82$ & Regional & Latin America & Meta-analysis \\
USA & 5.20 & $5.20-5.20$ & Country & & Single country (USA) \\
\hline
\end{tabular}

CI, confidence interval. *For meta-analysis estimates, the data given are the $95 \%$ CIs; for median estimates, the data given are the ranges in study estimates.

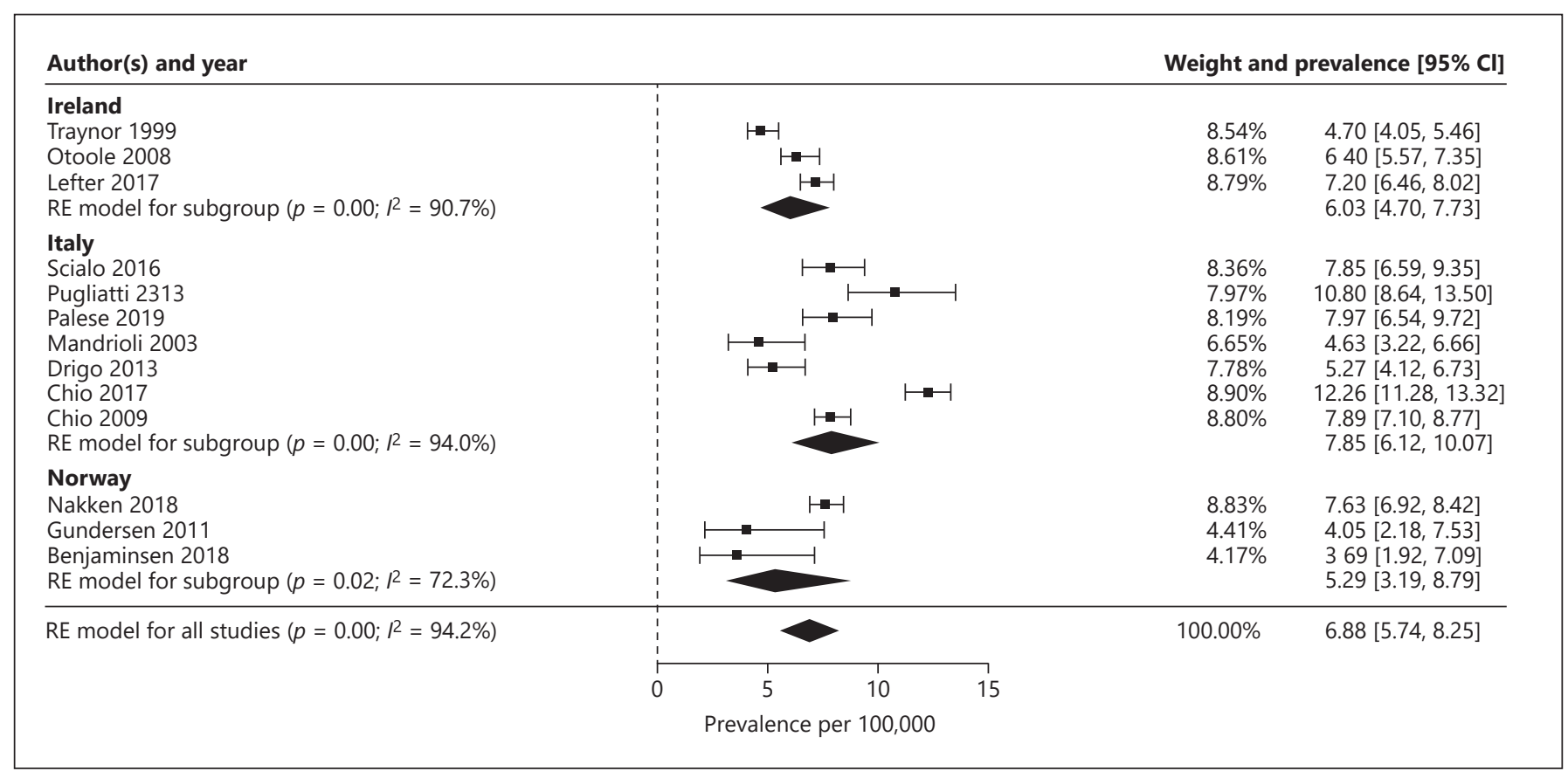

Fig. 4. Country-specific prevalence forest plot (meta-analysis in R). CI, confidence interval; RE, random effects. 


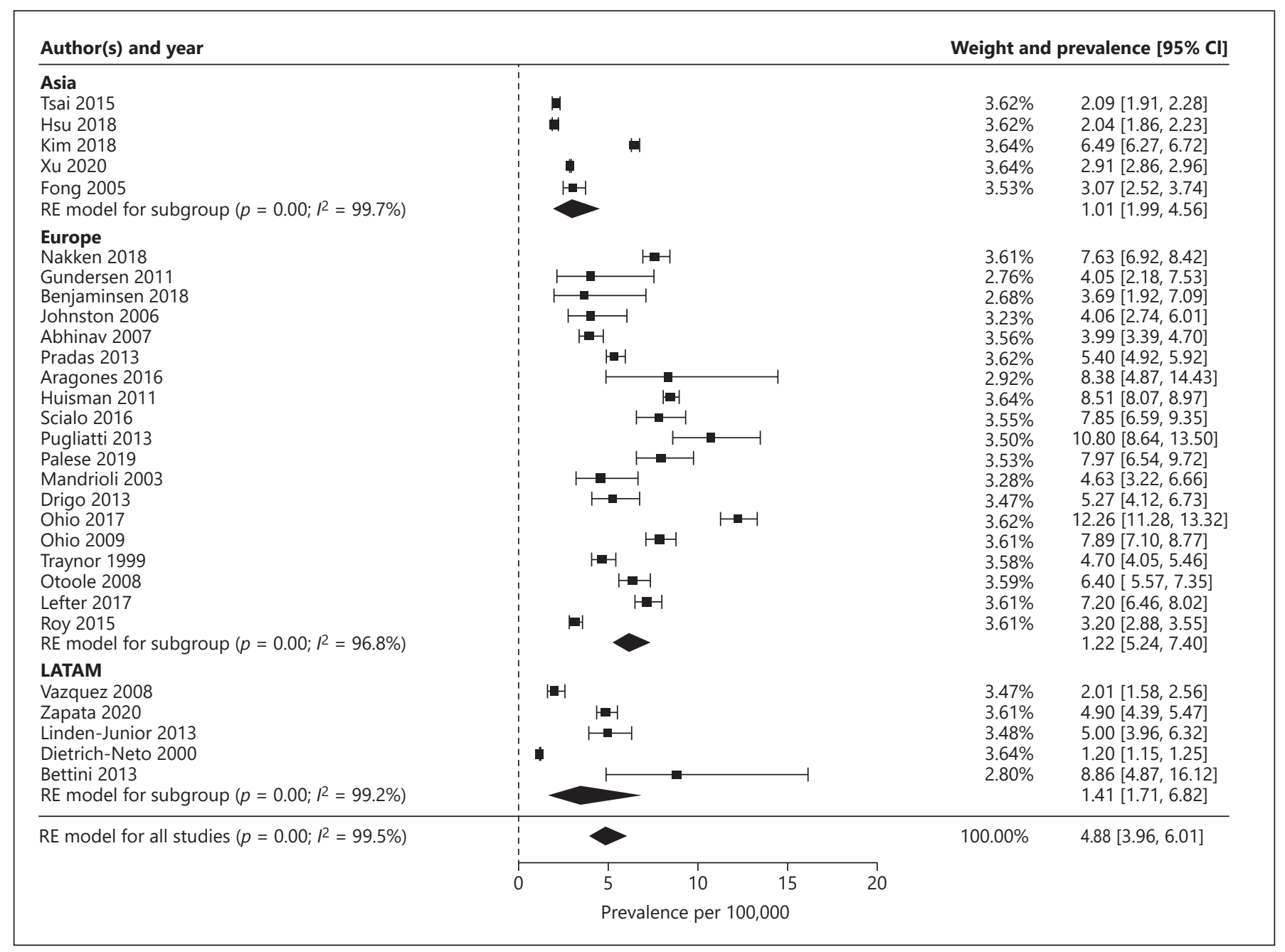

Fig. 5. Region-specific prevalence forest plot (meta-analysis in R). CI, confidence interval; RE, random effects.

These results show that the majority of SOD1 and C9orf72 ALS cases may be found among those with sALS and further highlight the fact that SOD1 and C9orf72 mutations are found not only in fALS cases but also in sALS cases. Although the proportions of SOD1 and C9orf72 mutations are higher among those with fALS, the higher prevalence of sALS cases results in estimates indicating that more SOD1 and C9orf72 ALS cases may be found among those with sALS (about 52 and 70\%, respectively). These results suggest that classification of fALS based on reported family history does not capture the full picture of ALS of genetic origin. Broader genetic testing is needed among those both with and without established family history to fully understand frequency and distribution of genetic mutations leading to ALS. Regional differences also appear to exist in the rates of SOD1 and C9orf72 mu- tations among fALS and sALS cases, with a notably higher frequency of C9orf72 mutations in European settings.

This analysis has several limitations. The country-specific age structure of the population was accounted for by using country- or regional-specific estimates. However, the age structure could change in the future, resulting in less applicable estimates. Second, we do not address any changes in survival over time. If survival improves in the future, due to changes in supportive care or therapy, the prevalence would tend to increase above the current estimates. Third, we found meaningful heterogeneity both within countries and between countries. To obtain a single estimate, we used the meta-analysis estimate, where there were 3 or more published estimates, as a central value. Additionally, many countries had no population-based data for incidence and/or prevalence; a regional estimate had 
to be used, and these regional estimates may not accurately reflect underlying country-specific rates, and the proportion of cases that were fALS was assumed constant. Furthermore, unrecognized flaws, statistical variation, or lack of representativeness of a study could affect summary estimates as well. Finally, the overall pooled estimates of SOD1 and C9orf72 frequency from the meta-analysis study by Zou et al. [2] among Asian and European populations were applied rather than country-level estimates. As SOD1 and C9orf72 frequency estimates at the country level are based on a relatively small number of cases and estimates were reported for some but not all countries, we opted to use the overall, more stable, pooled estimate for Asian and European populations.

Despite these cautions, this analysis contributes valuable insight into country and regional burden of ALS from 22 countries around the world. Future populationbased studies of ALS, from Asia, Latin America, and Central America in particular, will aid in improving the estimated total number of ALS cases globally. Increased genetic testing of sALS cases will lend further insight into the full genetic landscape of ALS and ultimately could support early detection and treatment.

\section{Acknowledgement}

Editorial support for the manuscript was provided by Jackie Parker and Miranda Dixon, Excel Scientific Solutions (Fairfield, CT, USA) and supported by Biogen (Cambridge, MA, USA).

\section{Statement of Ethics}

No patient-level data were used for this study.

\section{Conflict of Interest Statement}

C.A.B. was an employee of Epidemiologic Research \& Methods, LLC, which provided consulting services for Biogen (Cambridge, MA, USA) when the work on this manuscript was performed and completed; current affiliation is Amgen (Thousand Oaks, CA, USA). C.L. and W.D.F. are employees of Epidemiologic Research \& Methods, a consulting company whose clients include Biogen (Cambridge, MA, USA). V.K. is an employee of and holds stock/stock options in Biogen (Cambridge, MA, USA).

\section{Funding Sources}

The study was sponsored by Biogen (Cambridge, MA, USA).

\section{Author Contributions}

All the authors contributed to the conception or design of the work and analysis and interpretation of the data, as well as drafting the manuscript or revising it critically for content and providing the final approval of the version to be published. All the authors agree to be accountable for all aspects of the work in ensuring that questions related to the accuracy or integrity of any part of the work are appropriately investigated and resolved.

\section{References}

1 Chiò A, Logroscino G, Traynor BJ, Collins J, Simeone JC, Goldstein LA, et al. Global epidemiology of amyotrophic lateral sclerosis: a systematic review of the published literature. Neuroepidemiology. 2013;41(2):118-30.

2 Zou ZY, Zhou ZR, Che CH, Liu CY, He RL, Huang HP. Genetic epidemiology of amyotrophic lateral sclerosis: a systematic review and meta-analysis. J Neurol Neurosurg Psychiatry. 2017;88(7):540-9.

3 Kiernan MC, Vucic S, Cheah BC, Turner MR, Eisen A, Hardiman O, et al. Amyotrophic lateral sclerosis. Lancet. 2011;377(9769):942-55.

4 Rooney JPK, Brayne C, Tobin K, Logroscino G, Glymour MM, Hardiman O. Benefits, pitfalls, and future design of population-based registers in neurodegenerative disease. Neurology. 2017;88(24):2321-9.

5 Logroscino G, Traynor BJ, Hardiman O, Chio' A, Couratier P, Mitchell JD, et al. Descriptive epidemiology of amyotrophic lateral sclerosis: new evidence and unsolved issues. J
Neurol Neurosurg Psychiatry. 2008;79(1):611.

6 Abel O, Powell JF, Andersen PM, Al-Chalabi A. ALSoD: a user-friendly online bioinformatics tool for amyotrophic lateral sclerosis genetics. Hum Mutat. 2012;33(9):1345-51.

7 Schymick JC, Talbot K, Traynor BJ. Genetics of sporadic amyotrophic lateral sclerosis. Hum Mol Genet. 2007;16(R2):R233-42.

8 Cronin S, Hardiman O, Traynor BJ. Ethnic variation in the incidence of ALS: a systematic review. Neurology. 2007;68(13):1002-7.

9 Zaldivar T, Gutierrez J, Lara G, Carbonara M, Logroscino G, Hardiman O. Reduced frequency of ALS in an ethnically mixed population: a population-based mortality study. Neurology. 2009;72(19):1640-5.

10 Roberts AL, Johnson NJ, Chen JT, Cudkowicz ME, Weisskopf MG. Race/ethnicity, socioeconomic status, and ALS mortality in the United States. Neurology. 2016;87(22):23008.
11 Mehta P, Kaye W, Raymond J, Punjani R, Larson $\mathrm{T}$, Cohen J, et al. Prevalence of amyotrophic lateral sclerosis: United States, 2015. MMWR Morb Mortal Wkly Rep. 2018;67(46):1285-9.

12 Doi Y, Atsuta N, Sobue G, Morita M, Nakano I. Prevalence and incidence of amyotrophic lateral sclerosis in Japan. J Epidemiol. 2014; 24(6):494-9.

13 Bonaparte JP, Grant IA, Benstead TJ, Murray TJ, Smith M. ALS incidence in nova scotia over a 20-year-period: a prospective study. Can J Neurol Sci. 2007;34(1):69-73.

14 Golby R, Poirier B, Fabros M, Cragg JJ, Yousefi M, Cashman N. Five-year incidence of amyotrophic lateral sclerosis in British Columbia (2010-2015). Can J Neurol Sci. 2016;43(6): 791-5.

15 Lareau-Trudel E, Fortin E, Gauthier M, Lavoie S, Morissette E, Mathieu J. Epidemiological surveillance of amyotrophic lateral sclerosis in Saguenay region. Can J Neurol Sci. 2013;40(5):705-9. 
16 Fong GC, Cheng TS, Lam K, Cheng WK, Mok $\mathrm{KY}$, Cheung CM, et al. An epidemiological study of motor neuron disease in Hong Kong. Amyotroph Lateral Scler Other Motor Neuron Disord. 2005;6(3):164-8.

17 Xu L, Chen L, Wang S, Feng J, Liu L, Liu G, et al. Incidence and prevalence of amyotrophic lateral sclerosis in urban China: a national population-based study. J Neurol Neurosurg Psychiatry. 2020;91(5):520-5.

18 Zhang XR, Zhou WX, Zhang YX. Improvements in SOD mimic AEOL-10150, a potent broad-spectrum antioxidant. Mil Med Res. 2018;5(1):30

19 Marin B, Gil J, Preux PM, Funalot B, Couratier P. Incidence of amyotrophic lateral sclerosis in the Limousin region of France, 19972007. Amyotroph Lateral Scler. 2009;10(4): 216-20.

20 Marin B, Hamidou B, Couratier P, Nicol M, Delzor A, Raymondeau M, et al. Populationbased epidemiology of amyotrophic lateral sclerosis (ALS) in an ageing Europe: the French register of ALS in Limousin (FRALim register). Eur J Neurol. 2014;21(10):1292-9. e78-9.

21 Masseret E, Banack S, Boumédiène F, Abadie E, Brient L, Pernet F, et al. Dietary BMAA exposure in an amyotrophic lateral sclerosis cluster from southern France. PLoS One. 2013;8(12):e83406.

22 Rosenbohm A, Peter RS, Erhardt S, Lulé D, Rothenbacher D, Ludolph AC, et al. Epidemiology of amyotrophic lateral sclerosis in Southern Germany. J Neurol. 2017;264(4) 749-57.

23 Uenal H, Rosenbohm A, Kufeldt J, Weydt P, Goder K, Ludolph A, et al. Incidence and geographical variation of amyotrophic lateral sclerosis (ALS) in Southern Germany: completeness of the ALS registry Swabia. PLoS One. 2014;9(4):e93932.

24 Wolf J, Wöhrle JC, Palm F, Nix WA, Maschke $\mathrm{M}$, Safer A, et al. Incidence of amyotrophic lateral sclerosis in Rhineland-Palatinate, Germany. Amyotroph Lateral Scler Frontotemporal Degener. 2014;15(3-4):269-74.

25 Logroscino G, Traynor BJ, Hardiman O, Chiò A, Mitchell D, Swingler RJ, et al. Incidence of amyotrophic lateral sclerosis in Europe. Neurol Neurosurg Psychiatry. 2010;81(4): 385-90.

26 O'Toole O, Traynor BJ, Brennan P, Sheehan C, Frost E, Corr B, et al. Epidemiology and clinical features of amyotrophic lateral sclerosis in Ireland between 1995 and 2004. J Neurol Neurosurg Psychiatry. 2008;79(1): $30-2$.

27 Traynor BJ, Codd MB, Corr B, Forde C, Frost E, Hardiman O. Incidence and prevalence of ALS in Ireland, 1995-1997: a populationbased study. Neurology. 1999;52(3):504-9.

28 Bandettini di Poggio M, Sormani MP, Truffelli R, Mandich P, Origone P, Verdiani S, et al. Clinical epidemiology of ALS in Liguria, Italy. Amyotroph Lateral Scler Frontotemporal Degener. 2013;14(1):52-7.
29 Beghi E, Millul A, Micheli A, Vitelli E, Logroscino G. Incidence of ALS in Lombardy, Italy. Neurology. 2007;68(2):141-5.

30 Chiò A, Traynor BJ, Lombardo F, Fimognari M, Calvo A, Ghiglione P, et al. Prevalence of SOD1 mutations in the Italian ALS population. Neurology. 2008;70(7):533-7.

31 Chiò A, Mora G, Moglia C, Manera U, Canosa A, Cammarosano S, et al. Secular trends of amyotrophic lateral sclerosis: the Piemonte and Valle d'Aosta register. JAMA Neurol. 2017;74(9):1097-104.

32 Cima V, Logroscino G, D’Ascenzo C, Palmieri A, Volpe M, Briani C, et al. Epidemiology of ALS in Padova district, Italy, from 1992 to 2005. Eur J Neurol. 2009;16(8):920-4.

33 Drigo D, Verriello L, Clagnan E, Eleopra R, Pizzolato G, Bratina A, et al. The incidence of amyotrophic lateral sclerosis in Friuli Venezia Giulia, Italy, from 2002 to 2009: a retrospective population-based study. Neuroepidemiology. 2013;41(1):54-61.

34 Georgoulopoulou E, Vinceti M, Bonvicini F, Sola P, Goldoni CA, De Girolamo G, et al. Changing incidence and subtypes of ALS in Modena, Italy: a 10-years prospective study. Amyotroph Lateral Scler. 2011;12(6):451-7.

35 Giagheddu M, Puggioni G, Tacconi P, Pirastru MI, Cannas A, Tamburini G, et al. Amyotrophic lateral sclerosis in Sardinia (Italy): epidemiologic features from 1957 to 2000. Acta Neurol Scand. 2013;127(4):251-9.

36 Logroscino G, Beghi E, Zoccolella S, Palagano $\mathrm{R}$, Fraddosio A, Simone IL, et al. Incidence of amyotrophic lateral sclerosis in southern Italy: a population based study. J Neurol Neurosurg Psychiatry. 2005;76(8):1094-8.

37 Mandrioli J, Biguzzi S, Guidi C, Venturini E, Sette E, Terlizzi E, et al. Epidemiology of amyotrophic lateral sclerosis in Emilia Romagna Region (Italy): a population based study. Amyotroph Lateral Scler Frontotemporal Degener. 2014;15(3-4):262-8.

38 Mandrioli J, Faglioni P, Merelli E, Sola P. The epidemiology of ALS in Modena, Italy. Neurology. 2003;60(4):683-9.

39 Nicoletti A, Vasta R, Venti V, Mostile G, Lo Fermo S, Patti F, et al. The epidemiology of amyotrophic lateral sclerosis in the Mount Etna region: a possible pathogenic role of volcanogenic metals. Eur J Neurol. 2016;23(5): 964-72.

40 Palese F, Sartori A, Logroscino G, Pisa FE. Predictors of diagnostic delay in amyotrophic lateral sclerosis: a cohort study based on administrative and electronic medical records data. Amyotroph Lateral Scler Frontotemporal Degener. 2019;20(3-4):176-85

41 Piemonte, Valle d'Aosta Register for Amyotrophic Lateral Sclerosis. Incidence of ALS in Italy: evidence for a uniform frequency in Western countries. Neurology. 2001;56(2): 239-44.

42 Pugliatti M, Parish LD, Cossu P, Leoni S, Ticca A, Saddi MV, et al. Amyotrophic lateral sclerosis in Sardinia, insular Italy, 1995-2009. J Neurol. 2013;260(2):572-9.
43 Ragonese P, Cellura E, Aridon P, D'Amelio M, Spataro R, Taiello AC, et al. Incidence of amyotrophic lateral sclerosis in Sicily: a population based study. Amyotroph Lateral Scler. 2012;13(3):284-7.

44 Scialò C, Novi G, Bandettini di Poggio M, Canosa A, Sormani MP, Mandich P, et al. Clinical epidemiology of amyotrophic lateral sclerosis in Liguria, Italy: an update of LIGALS register. Amyotroph Lateral Scler Frontotemporal Degener. 2016;17(7-8):53542.

45 Tesauro M, Consonni M, Filippini T, Mazzini L, Pisano F, Chiò A, et al. Incidence of amyotrophic lateral sclerosis in the province of Novara, Italy, and possible role of environmental pollution. Amyotroph Lateral Scler Frontotemporal Degener. 2017;18(3-4):28490.

46 Benjaminsen E, Alstadhaug KB, Gulsvik M, Baloch FK, Odeh F. Amyotrophic lateral sclerosis in Nordland county, Norway, 20002015: prevalence, incidence, and clinical features. Amyotroph Lateral Scler Frontotemporal Degener. 2018;19(7-8):522-7.

47 Gundersen MD, Yaseen R, Midgard R. Incidence and clinical features of amyotrophic lateral sclerosis in Møre and Romsdal County, Norway. Neuroepidemiology. 2011;37(1):5863.

48 Aragones JM, Altimiras J, Roura-Poch P, Homs E, Bajo L, Povedano M, et al. Amyotrophic lateral sclerosis: a higher than expected incidence in people over 80 years of age. Amyotroph Lateral Scler Frontotemporal Degener. 2016;17(7-8):522-7.

49 Pradas J, Puig T, Rojas-García R, Viguera ML, Gich I, Logroscino G. Amyotrophic lateral sclerosis in Catalonia: a population based study. Amyotroph Lateral Scler Frontotemporal Degener. 2013;14(4):278-83.

50 Harper CJ, Sorenson EJ, Mandrekar J. Epidemiology of amyotrophic lateral sclerosis in Minnesota: a year-long population based study. Amyotroph Lateral Scler Frontotemporal Degener. 2015;16(7-8):520-3.

51 Wagner L, Rechtman L, Jordan H, Ritsick M, Sanchez M, Sorenson E, et al. State and metropolitan area-based amyotrophic lateral sclerosis (ALS) surveillance. Amyotroph Lateral Scler Frontotemporal Degener. 2016; 17(1-2):128-34.

52 Abhinav K, Stanton B, Johnston C, Hardstaff J, Orrell RW, Howard R, et al. Amyotrophic lateral sclerosis in South-East England: a population-based study. The South-East England register for amyotrophic lateral sclerosis (SEALS Registry). Neuroepidemiology. 2007; 29(1-2):44-8.

53 Forbes RB, Colville S, Parratt J, Swingler RJ. The incidence of motor nueron disease in Scotland. J Neurol. 2007;254(7):866-9.

54 Johnston CA, Stanton BR, Turner MR, Gray $\mathrm{R}$, Blunt AH, Butt D, et al. Amyotrophic lateral sclerosis in an urban setting: a population based study of inner city London. J Neurol. 2006;253(12):1642-3. 
55 Bettini M, Vicens J, Giunta DH, Rugiero M, Cristiano E. Incidence and prevalence of amyotrophic lateral sclerosis in an HMO of Buenos Aires, Argentina. Amyotroph Lateral Scler Frontotemporal Degener. 2013;14(7-8): 598-603.

56 Dietrich-Neto F, Callegaro D, Dias-Tosta E, Silva HA, Ferraz ME, Lima JM, et al. Amyotrophic lateral sclerosis in Brazil: 1998 national survey. Arq Neuropsiquiatr. 2000;58(3a): 607-15.

57 Zapata CHZ, Franco Dáger E, Aguirre-Acevedo DC, De Carvalho M, Solano-Atehortúa J. Prevalence, incidence, and clinical-epidemiological characterization of amyotrophic lateral sclerosis in Antioquia: Colombia. Neuroepidemiology. 2019;54(3):251-7.

58 Vázquez MC, Ketzoián C, Legnani C, Rega I, Sánchez N, Perna A, et al. Incidence and prevalence of amyotrophic lateral sclerosis in Uruguay: a population-based study. Neuroepidemiology. 2008;30(2):105-11.

59 Preux PM, Druet-Cabanac M, Couratier P, Debrock C, Truong T, Marcharia W, et al. Estimation of the amyotrophic lateral sclerosis incidence by capture-recapture method in the Limousin region of France. J Clin Epidemiol. 2000;53(10):1025-9.

60 Kim JM, Park JH, Kim HS, Lee JW, Lim HS, Choi WA, et al. Epidemiology and diagnostic process of amyotrophic lateral sclerosis as distinct from myelopathy: 5-year cohort study of whole-population in South Korea. Amyotroph Lateral Scler Frontotemporal Degener. 2018;19(7-8):547-54.

61 Tsai CP, Wang KC, Hwang CS, Lee IT, Lee $\mathrm{CT}$. Incidence, prevalence, and medical expenditures of classical amyotrophic lateral sclerosis in Taiwan, 1999-2008. J Formos Med Assoc. 2015;114(7):612-9.
62 Zhou Qian S, Zhou Y, Qian S, Chang W, Wang L, Fan D. Amyotrophic lateral sclerosis in Beijing: epidemiologic features and prognosis from 2010 to 2015. Brain Behav. 2018; 8(11):e01131.

63 Palese F, Sartori A, Verriello L, Ros S, Passadore $\mathrm{P}$, Manganotti P, et al. Epidemiology of amyotrophic lateral sclerosis in Friuli-Venezia Giulia, North-Eastern Italy, 2002-2014: a retrospective population-based study. Amyotroph Lateral Scler Frontotemporal Degener. 2019;20(1-2):90-9.

64 Kihira T, Yoshida S, Hironishi M, Miwa H, Okamato K, Kondo T. Changes in the incidence of amyotrophic lateral sclerosis in Wakayama, Japan. Amyotroph lateral scler other motor. Neuron Disord. 2005;6(3):15563.

65 Hsu JC, Wu HC, Feng WC, Chou CH, Lai ECC, Lu CY. Disease and economic burden for rare diseases in Taiwan: a longitudinal study using Taiwan's National health insurance research database. PLoS One. 2018; 13(9):e0204206.

66 Roy AJ, Van den Bergh P, Van Damme P, Doggen K, Van Casteren V. Early stages of building a rare disease registry, methods and 2010 data from the Belgian neuromuscular disease registry (BNMDR). Acta Neurol Belg. 2015;115(2):97-104

67 Lefter S, Hardiman O, Ryan AM. A population-based epidemiologic study of adult neuromuscular disease in the Republic of Ireland. Neurology. 2017;88(3):304-13.

68 Chio A, Calvo A, Dossena M, Ghiglione P, Mutani R, Mora G. ALS in Italian professional soccer players: the risk is still present and could be soccer-specific. Amyotroph Lateral Scler. 2009;10(4):205-9.

69 Huisman MH, de Jong SW, van Doormaal PT, Weinreich SS, Schelhaas HJ, van der Kooi AJ, et al. Population based epidemiology of amyotrophic lateral sclerosis using capturerecapture methodology. J Neurol Neurosurg Psychiatry. 2011;82(10):1165-70.
70 Linden-Junior E, Becker J, Schestatsky P, Rotta FT, Marrone CD, Gomes I. Prevalence of amyotrophic lateral sclerosis in the city of Porto Alegre, in Southern Brazil. Arq Neuropsiquiatr. 2013;71(12):959-62.

71 Mehta P, Kaye W, Raymond J, Punjani R, Larson T, Cohen J, et al. Prevalence of amyotrophic lateral sclerosis: United States, 2015. MMWR Morb Mortal Wkly Rep. 2018; 67(46):1285-9.

72 Eurostat, European Commission. Population on 1st January by age, sex and type of projection. European Union (28 Countries) Luxembourg. Eurostat, European Commission; 2019 [updated 2019 Jul 3]. Available from: http://ec.europa.eu/eurostat/data/database.

73 United Nations Department of Economic and Social Affairs. World population prospects 2019 revision. DVD Edition; 2019.

74 Statistics Canada. Table 17-10-0057-01. Projected population, by projection scenario, age and sex, as of July $1(\times 1,000)$. Canada: Statistics Canada; 2020.

75 National population projections: United States by age, gender, ethnicity and race for the years 2014-2060 [Internet]. CDC Wonder; 2015. Available from: https://wonder. cdc.gov/WONDER/help/PopulationProjections-2060.HTML.

76 Byrne S, Walsh C, Lynch C, Bede P, Elamin $\mathrm{M}$, Kenna K, et al. Rate of familial amyotrophic lateral sclerosis: a systematic review and meta-analysis. J Neurol Neurosurg Psychiatry. 2011;82(6):623-7.

77 Marin B, Boumédiene F, Logroscino G, Couratier $\mathrm{P}, \mathrm{Babron} \mathrm{MC}$, Leutenegger $\mathrm{AL}$, et al. Variation in worldwide incidence of amyotrophic lateral sclerosis: a meta-analysis. Int J Epidemiol. 2017;46(1):57-74.

78 Logroscino G. Global, regional, and national burden of motor neuron diseases 1990-2016: a systematic analysis for the Global Burden of Disease Study 2016. Lancet Neurol. 2018; 17(12):1083-97. 